\title{
MULTIPLE CALCIFIC EMBOLISM FOLLOWING MITRAL VALVOTOMY
}

\author{
BY
}

\author{
M. J. T. ADAMS*
}

From the Bland Sutton Institute of Pathology, the Middlesex Hospital

Calcification of the valve is frequently encountered at valvotomy for the relief of mitral stenosis. Calcific embolism is a recognized hazard of the operation, but Michell (1960), who has reviewed the problem of valvular calcification with regard to mitral valvotomy, has stated that, "the danger from calcific emboli during valvotomy does not seem to be very great." Perhaps it is not always recognized, even at necropsy. The purpose of this paper is to report a case of multiple calcific embolism following mitral valvotomy, and to describe the methods used for the detection of these emboli.

\section{Case Report}

A woman, born in Hungary in 1926, contracted rheumatic fever at the age of fourteen. After this she remained well, apart from some breathlessness on exertion, and came to England in 1947. Two years later she had a hæmoptysis and developed pyrexia with further rheumatic pains, and was in bed for 18 weeks. Following this illness she suffered from recurrent respiratory infections, and in February 1952 she had an attack of congestive heart failure and was referred to Dr. Evan Bedford. She had signs of severe mitral stenosis with some aortic regurgitation, and calcification of the mitral valve was easily seen on radioscopy.

In April 1952, Mr. T. Holmes Sellors performed a mitral valvotomy. The valve orifice was only $2 \mathrm{~cm}$. long, and the edges were smooth but calcified. A good split was made anteriorly, but the posterior commissure was heavily calcified and could only be partially divided. She made an uneventful recovery and her exercise tolerance increased. Unfortunately the improvement lasted for only three years after which she began to get further chest infections, and in March 1957 she developed atrial fibrillation for the first time. Two months later she had a further attack of congestive heart failure and the physical signs were again indicative of severe mitral stenosis.

A diagnosis of re-stenosis of the mitral valve was made, and a further valvotomy was done by Mr. J. R. Belcher. A small adherent thrombus was found in the remains of the atrial appendage, and the whole valve ring was felt to be heavily calcified. A good split was made digitally: during the splitting the carotid arteries were compressed manually by external pressure. The patient was awake and able to move all four limbs before leaving the operating theatre. She remained rather more drowsy than usual, but otherwise her progress over the following 48 hours was quite satisfactory. She lost about $750 \mathrm{ml}$. of blood-stained fluid through the intercostal drainage tube, but an equivalent amount of blood was replaced by transfusion. On the third day after operation, she became confused and was found to have increased tendon reflexes in the left arm, and on the following day she died.

Necropsy. (Bland Sutton Institute of Pathology, P.M. No. 146/57). There were two small purpuric hæmorrhages in the palm of the left hand. The left pleural cavity contained about $800 \mathrm{ml}$. of clotted blood; no bleeding point was found. The mitral valve was grossly calcified and the edges of the opening rigid. There was a concomitant, but less severe, stenosis of the aortic valve with no apparent calcification, and the myocardium, the chambers of the heart, and the pulmonary artery all showed changes consistent with these valvular lesions. There was a small recent infarct in the left kidney. On the surface of the brain were several sub-arachnoid hæmorrhages up to $1.5 \mathrm{~cm}$. in diameter.

An unidentified medical student suggested that fragments of the irregular mitral valve might have become dislodged and impacted in the cortical blood vessels. A radiograph of the intact brain was taken and this showed many fragments of calcified material. In order to locate these fragments the brain was sliced and further radiographs taken (Fig. 1). When the brain was sliced no abnormality was seen within its substance, but on the radiographs twenty-one small opacities were seen, mostly around the surface of the brain and in close relation to the hæmorrhages. With the aid of a dissecting microscope the superficial cortical vessels in

$$
\text { * Now at Bristol General Hospital, Bristol, } 1 .
$$




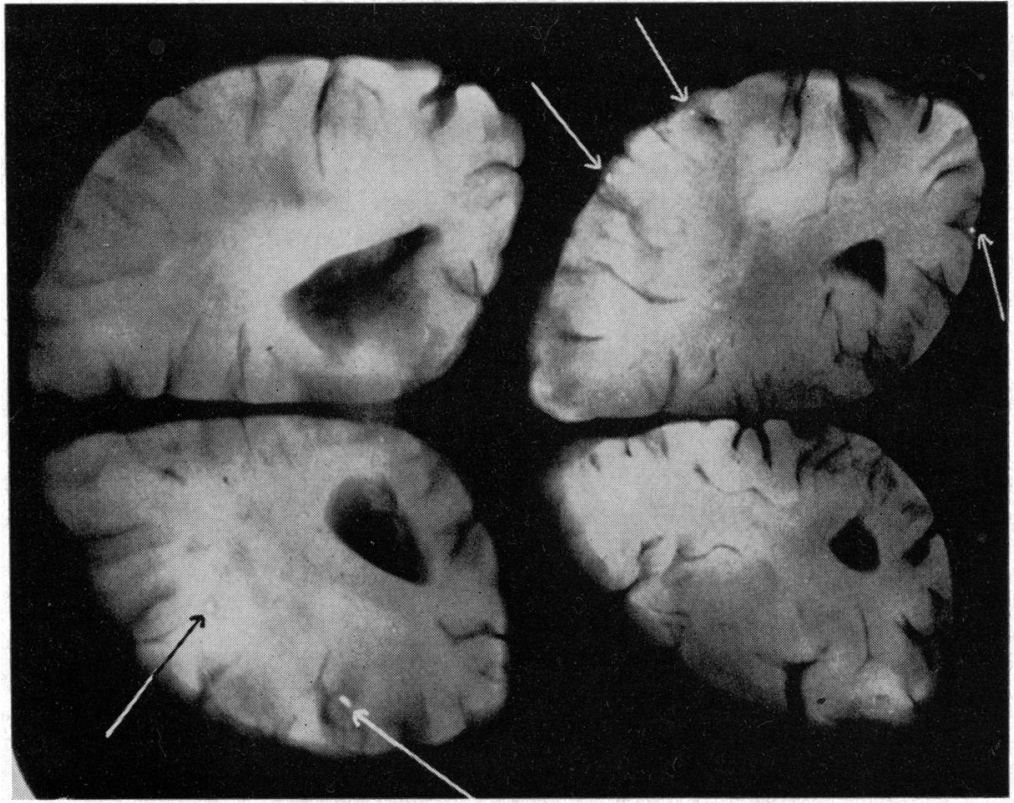

FIG. 1.-X-ray of two coronal sections of the brain, each approximately $1.5 \mathrm{~cm}$. thick. Two calcified opacities can be seen in the bottom left section, and three in the top right section.

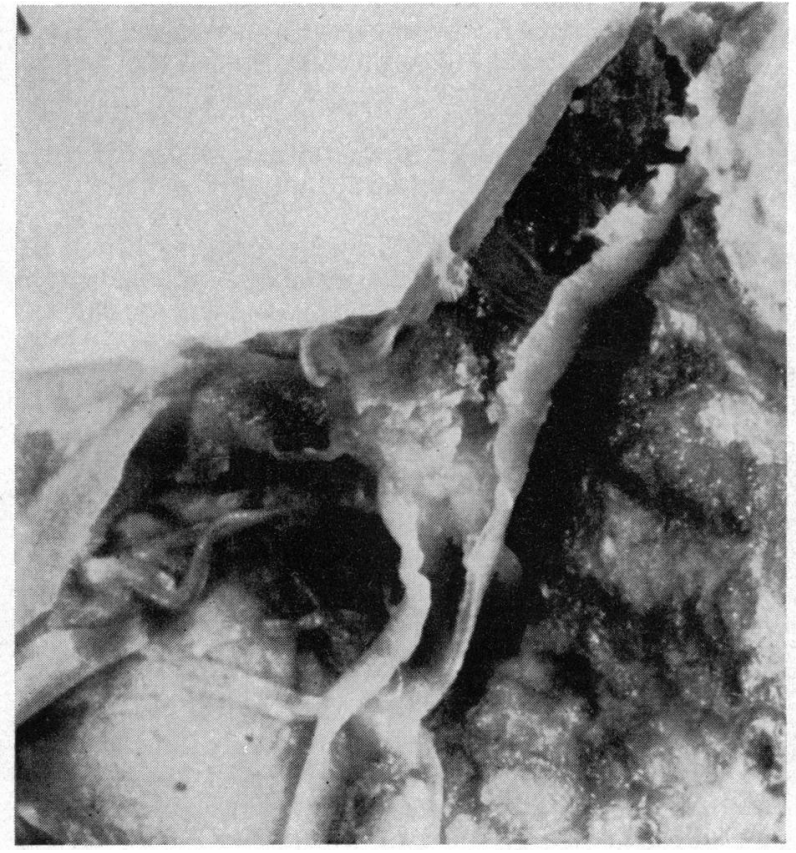

Fig. 2.-Superficial cortical blood vessel opened. At the bifurcation of the vessel a white calcific fragment can be seen, and proximal to the fragment is an ante-mortem thrombus $(\times 10)$.

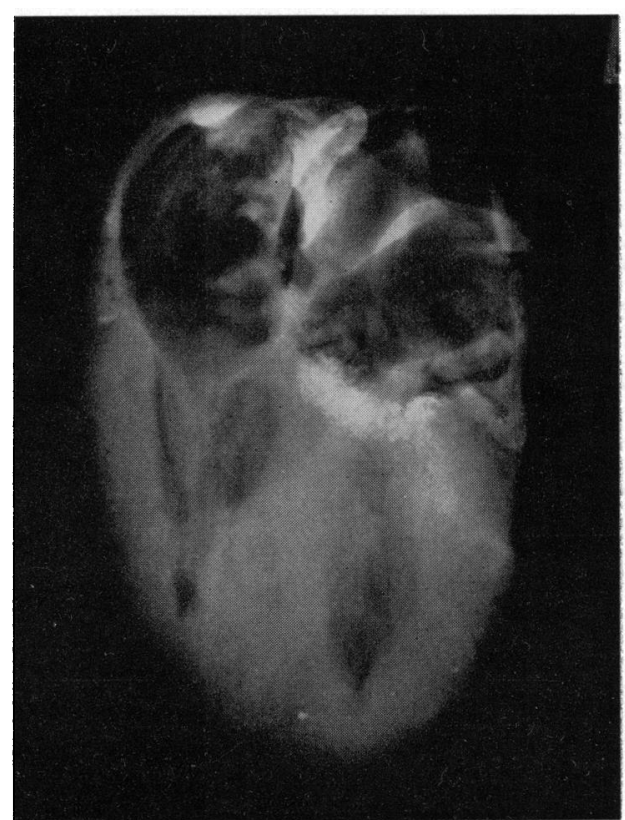

Fig. 3.-X-ray of the heart, showing peripheral calcific opacities and calcification in the mitral valve. 
the region of two of the opacities were opened. In each specimen the vessel was occluded by a fragment of stony hard material, which, on analysis, proved to be composed mainly of calcium phosphate (Fig.2). These fragments were not attached to the vessel walls, and were undoubtedly true emboli. In the specimen illustrated there was an associated ante-mortem thrombus proximal to the obstruction. In order to demonstrate the calcification in the mitral valve a radiograph was taken of the heart (Fig. 3). Unexpectedly two further small opacities were seen at the periphery of the heart, and these proved on dissection to be similar calcific emboli in the branches of the coronary arteries; there was no associated thrombosis and careful examination of the neighbouring myocardium did not reveal any evidence of infarction.

\section{Discussion}

The incidence of valvular calcification found at mitral valvotomy in the series of Sellors et al. (1953) was 31 per cent, and Bailey $(1955, a)$ found it in 39 per cent of his cases. Three deaths due to proven cerebral calcific embolism have been reported by Bolton et al. (1952), Bailey and Morse (1957), and Barr and Sommers (1957). In the first two of these there was profound paralysis following the operation, and in the third there was a severe drop in the blood pressure and cessation of respiration during the splitting of the valve: in all of them a major cerebral vessel was occluded and death occurred within 36 hours. Two cases of multiple calcific emboli have been recorded by Harken and Black (1955). In the first of these the patient developed severe cardiac arrhythmia following the operation and died within 24 hours: several loose calcific fragments were found in the coronary arteries. The second case, which is presumptive because he survived, was of a man, found at valvotomy to have a friable calcific valve, who had a left-sided hemiplegia and a posterior cardiac infarct immediately after the operation.

The unusual features of the case under discussion in this paper are the large number of emboli, and the lapse of time between the valvotomy and death. The most likely time for embolism to occur is during the manipulations in the atrium. It is probable that at least some of the cerebral emboli happened at that time, and were responsible for the patient's continued drowsiness following her recovery from anæsthesia. This does not necessarily mean that the carotid artery compression was inadequate, for in Barr and Sommers' case quoted above, the embolus lodged in the right vertebral artery, in spite of the fact that the carotid arteries were at no time occluded. The antemortem thrombus found in one of the cerebral vessels dissected also indicates that this embolus occurred some time before death. The development of mental confusion and spasticity in the left arm on the third post-operative day suggests that further emboli occurred after the operation. Cases of spontaneous coronary artery embolism by calcific particles associated with calcified aortic valves have been recorded by Moragues et al. (1950) and Wigle (1957), and it seems very likely that fragments of a diseased mitral valve could become dislodged at any time.

The commonly accepted figure for embolism of all kinds following mitral valvotomy lies between 4 per cent and 7 per cent (Bland, 1952; Sellors et al., 1953; Bailey, 1955, $b$; and Windsor, 1956). Wigle (1957) describes the case of a man who died one year after mitral valvotomy when the valve was heavily calcified, in whom a patch of myocardial fibrosis was found distal to an impacted fragment of calcified material at the bifurcation of the right coronary artery: this was not suspected during life. It is probable that the majority of emboli in the case under discussion would not have caused any disturbance, and, in view of their widespread distribution, it is possible that small calcific emboli are more common than is generally recognized.

\section{Summary}

The case history is presented of a woman aged 31, suffering from advanced rheumatic valvular disease of the heart, who died four days after a second mitral valvotomy. At necropsy several calcific emboli were found. The significance of these emboli is discussed.

I am grateful to Dr. D. Evan Bedford and to Mr. J. R. Belcher for their advice and for permission to publish this case. I am indebted to Mr. M. Turney for the photographs. 


\section{References}

Bailey, C. P. (1955). Surgery of the Heart. 1st ed., (a) p. 639, (b) p. 544. and Morse, D. P. (1957). J. thorac. Surg., 33, 427.

Barr, R. W., and Sommers, S. C. (1957). Amer. Heart J., 53, 232.

Bland, E. E. (1952). Circulation, 5, 290.

Bolton, H. E., Molignia, R., and Massey, F. C. (1952). J. thorac. Surg., 24, 502.

Harken, D. E., and Black, H. (1955). New England J. Med., 253, 669.

Michell, G. (1960). Brit. med. J., 1, 687.

Moragues, V., Bawell, M. B., and Schrader, E. L. (1950). Circulation, 2, 434.

Sellors, T. H., Bedford, D. E., and Somerville, W. (1953). Brit. med. J., 2, 1059.

Wigle, E. D. (1957). Brit. Heart J., 19, 539.

Windsor, H. M. (1956). $\quad$ Aust. N.Z. J. Surg., 25, 248. 